\title{
CTCF May Not Directly Regulate ER $\alpha$ mRNA Expression in the ER+ MCF7 Breast Cancer Cell Line
}

Okezie Ofor*, Helen Moor, David Humber and Christina Greenwood

Postgraduate Medical Institute, Anglia Ruskin University, Cambridge and Chelmsford, UK

\begin{abstract}
Introduction: CTCF is an evolutionally conserved 11-zinc finger protein factor involved in an array of processes whose deregulation could lead to cellular transformation. Through interactions with ERa binding regions and ERregulated genes, CTCF was shown to compartmentalize the cellular genome into domains. It also colocalized with ERa in MCF7 cells and had interactions with ERa during histone deacetylase recruitment and fork-head activity. A fast-running isoform was previously shown to be expressed in breast cancer tissue but not in normal breast tissue. It is not clear whether there is a regulatory relationship between CTCF and ER $\alpha$ in breast cancer.
\end{abstract} line.

Aim: To determine whether CTCF expression regulated ER $\alpha$ expression in the ER+ MCF7 breast cancer cell

Methods: MCF7 breast cancer cells were transfected with either CTCF expression vectors or siRNA against CTCF. Following CTCF over-expression and knock-down, changes in endogenous expression of ERa gene and protein expression were monitored by quantitative polymerase chain reaction (using MIQE guidelines) and western blot analysis respectively.

Results: CTCF plasmid overexpression and siRNA knockdown was associated with cell rounding but with $96.4 \%$ and $95.7 \%$ cell viability respectively. Increase in CTCF mRNA on over-expression was associated with a rise in CTCF protein expression. siRNA knockdown of CTCF mRNA was accompanied by a corresponding decrease in CTCF protein expression. CTCF over-expression and knockdown appeared to inhibit the ability to detect ERa protein expression by western blotting. Neither the over-expression nor knockdown of CTCF altered ERa mRNA expression as detected by QPCR.

Conclusion: Alterations in CTCF mRNA expression did not affect ERa gene expression in MCF7 cells suggesting that CTCF interactions with the estrogen receptor in breast cancer may not be mediated via direct regulation of ERa mRNA expression.

\section{Keywords: CTCF; Breast cancer; MCF7; ERa; MIQE; QPCR}

\section{Introduction}

CTCF is an 11 zinc finger protein factor involved in cellular activities which include gene expression regulation, cellular architectural organization, long range chromatin interactions, insulation and genomic imprinting $[1,2]$. These varied activities are mediated with multiple combinations of its 11 zinc fingers with subsequent phenotype possibly determined by protein partners [3] and post translational modifications $[4,5]$. Dysregulation of these processes could lead to cellular transformation. Indeed a fast running CTCF isoform was specifically found expressed in breast cancer tissue but not in normal breast tissue and lower expression level of this isoform was associated with worse prognostic indices [6].

Initial evidence supporting the role of estrogen in breast cancer was found in MCF 10A and MCF 10F cells which are immortalized estrogen - and progesterone - receptor negative, breast epithelial cell lines $[7,8]$. These cells were transformed on estrogen stimulation as evidenced by the acquisition of anchorage-independent growth, loss of their usual duct pattern, invasiveness on Matrigel and induction of palpable tumors in severe combined immune-deficient (SCID) mice $[7,8]$. Though the fore mentioned studies observed the transforming effect of estrogen, they did not comment on how estrogen gained entry seeing that the cells were estrogen receptor (ER) negative. The ER expression status of a cell is defined by nuclear immunohistochemical staining but it is now clear that ER is also expressed on the cell membrane as well as in the cell cytoplasm [9-11]. Those cells typically classified as ER negative could also possess ER on the cell membranes as well as the cytoplasm and this might explain how estrogen gained entry into ER negative cells. More recent evidence linking estrogen and breast cancer was provided in a prospective case - control study which assessed the link with liquid chromatography/tandem mass spectrometry [12]. This study found a statistically significant association between unconjugated estradiol, high methylation levels of the 4-hydroxylation product of estradiol and increased breast cancer risk in a cohort of 277 postmenopausal patients. Taken together, estrogen therefore possessed a direct breast cell mitogenic effect and was also a precursor to a potent mutagen namely excessively methylated 4-hydroxylation products [12,13].

An accumulating body of evidence has pointed to a relationship between CTCF and ER $\alpha$ in breast cancer. This body of evidence indicates that first, exogenous estrogen (E2) down regulated CTCF mRNA expression in the ER+ MCF7 cells, an effect that was greater at higher estrogen concentrations [14]. Furthermore, the CTCF

*Corresponding author: Ofor O, Postgraduate Medical Institute, Anglia Ruskin University, Cambridge and Chelmsford, East Rd, Cambridge CB1 1PT, UK, Tel: +441245493131; E-mail: okezieofor@doctors.org.uk

Received January 25, 2016; Accepted March 15, 2016; Published March 17 2016

Citation: Ofor O, Moor H, Humber D, Greenwood C (2016) CTCF May Not Directly Regulate ERa mRNA Expression in the ER+ MCF7 Breast Cancer Cell Line. J Cancer Sci Ther 8: 059-065. doi:10.4172/1948-5956.1000391

Copyright: (c) 2016 Ofor O, et al. This is an open-access article distributed under the terms of the Creative Commons Attribution License, which permits unrestricted use, distribution, and reproduction in any medium, provided the original author and source are credited. 
promoter was found to harbor the estrogen response element (ERE) consensus sequence suggesting that the CTCF promoter could be a target for ERa [14]. Estrogen stimulation also recruited CTCF to the CDKN1c promoter leading to epigenetic silencing of that promoter possibly via methylation [15]. Second, investigation using ChIP - Seq showed that estrogen - down regulated gene regions were more likely to be co-bound by CTCF and ER than by either alone in MCF7 cells. Also CTCF and ER binding events were found to colocalise and there was significant ERE and CTCF motif enrichment in those colocalised regions. Despite evidence for colocalisation, we did not demonstrate physical binding between CTCF and ER $\alpha$ on mass spectrometry in MCF7 cells (manuscript in preparation). Third, Ross-Innes, et al. [16] discovered that CTCF compartmentalized the genome in MCF7 cells into domains that contained ERa binding regions and ERregulated genes. Fourth, the fork head protein (FOXA1/HNF3 $\alpha$ ) which modulates $\mathrm{ER} \alpha$ - chromatin interactions and is an absolute requirement for ERa binding to ER promoters (even in the absence of E2 binding) is itself negatively regulated by CTCF [17]. Fifth and finally, both CTCF and ER $\alpha$ recruited histone de-acetylase (HDAC) which via histone deacetylation repressed gene expression $[18,19]$.

Taken together, these pieces of evidence suggested a link between CTCF and ERa but the exact nature of that connection is not clear Seeing that recent evidence suggested that CTCF and ERa colocalised but were not physically bound (manuscript in preparation) this paper therefore investigated a possible direct regulatory effect of CTCF on ERa expression in the ER positive MCF7 breast cancer cell line.

\section{Materials and Methods}

\section{Breast cancer cell (BCC) lines and cell culture}

MCF7 (ER+/PR+, HER2-) cells were cultured in DMEM/Ham's F12 medium (Life Technologies, UK). Cells were passaged when they reached $70 \%-80 \%$ and cell work was performed as described in Docquier, et al. [6]. Cells were obtained from the European cell bank and were used up within 6 months of purchase.

\section{Cell lysate for western blot analysis}

$20 \mu \mathrm{l}$ of $2 \mathrm{x}$ lysis/loading buffer was mixed with $1 \times 10^{5}$ cells and the solution immediately vortexed (Whitimixer ${ }^{\mathrm{TM}}$, Fisherbrand) to resuspend the cell pellet. Heating at $95^{\circ} \mathrm{C}$ with a heating block (TECHNE, USA) for 5 minutes was done and lysates were used immediately or frozen at $-20^{\circ} \mathrm{C}$ for use at a later date.

\section{Trypan blue test for cell viability}

Cell suspension was prepared as described in Docquier, et al. [6]. $200 \mu \mathrm{l}$ of this suspension was placed in an Eppendorf tube containing $500 \mu \mathrm{l}$ of $0.4 \%$ trypan blue solution (Sigma, UK) and $300 \mu \mathrm{l}$ of Hanks' Balanced salt solution (GIBCO, UK). The solution was mixed thoroughly and allowed to stand for 10 minutes at room temperature. $10 \mu \mathrm{l}$ of the solution was introduced into a counting chamber and cells counted using a haemocytometer (Neubauer chamber - Marienfeld ${ }^{\mathrm{TM}}$, Germany).

\section{Bovine serum albumin protein assay}

BSA (Sigma, USA) standards were thawed at room temperature and $10 \mu \mathrm{l}$ of each pipetted at the bottom of 7 wells of a labelled 96 well micro titre plate (BioRad, USA) in duplicate. A further $10 \mu \mathrm{l}$ of distilled water and an equal volume of the buffer used to prepare lysates were pippetted to the bottom of the 8th and 9th wells in duplicate to serve as negative controls. Furthermore, $10 \mu \mathrm{l}$ each of a 1:1 and 1:2 dilution of the cell lysate sample to be tested was placed at the bottom of the 10th and 11th wells also in duplicate. One part of the dye reagent concentrate (BioRad, USA) was diluted with 4 parts of deiodised water (Bio-Rad, USA) and $200 \mu \mathrm{l}$ of the solution pipetted to each of the 11 wells in duplicate and mixed gently. The plate was allowed to stand at room temperature for 30 minutes and placed in a spectrophotometer (BioRad, USA) with absorbance measured at $595 \mathrm{~nm}$. A graph plotting absorbance versus BSA standard concentrations was created and a best fit line drawn to determine protein concentrations.

\section{RNA extraction}

To lyse and release RNA from incubated cells, $1 \mathrm{ml}$ of TRIsure (Bioline, UK) was placed into each well of a 12 well plate and incubated at room temperature for 5 minutes with gentle rocking and pipetting. In order to separate the three different phases into which lysed cells partition, $0.2 \mathrm{ml}$ of chloroform was added and solution shaken vigorously by hand for 15 seconds and incubated at room temperature for 3 minutes. Centrifugation at 12000x $g$ (Eppendorf centrifuge 5415 $\mathrm{R}$, Germany) for 15 minutes at $4^{\circ} \mathrm{C}$ was subsequently performed and the colourless upper aqueous phase (containing RNA) taken, mixed with $0.5 \mathrm{ml}$ ice cold isopropanol and incubated at room temperature for 10 minutes. It was centrifuged at $12000 \mathrm{x} g$ (Eppendorf centrifuge $5415 \mathrm{R}$, Germany) for 15 minutes at $4^{\circ} \mathrm{C}$ to precipitate RNA. The supernatant was removed and pellet washed in $1 \mathrm{ml}$ of $75 \%$ ethanol by inverting. Further centrifugation at $7500 \mathrm{x} g$ for 5 minutes at $4^{\circ} \mathrm{C}$ was done and the pellet allowed to air dry for at least 10 minutes. It was then dissolved in $45 \mu \mathrm{l}$ of RNAse free water (Fisher, USA) and incubated for 10 minutes at $55^{\circ} \mathrm{C}$. To remove contaminating DNA, $5 \mu$ l of $10 \mathrm{x}$ Turbo DNAse buffer ( $1 \mathrm{x}$ final) (Ambion, USA) and $1 \mu \mathrm{l}$ of Turbo DNAse ( $2 \mathrm{U} /$ $\mu \mathrm{l}$ ) (Ambion, USA) were added and solution incubated at $37^{\circ} \mathrm{C}$ for 30 minutes. $0.1(10 \%)$ volume DNAse inactivation agent (Ambion, USA) was added, solution incubated for 2 minutes at room temperature (RT) and centrifuged at 10,000x $g$ (Eppendorf centrifuge $5415 \mathrm{R}$, Germany) for 2 minutes at $4^{\circ} \mathrm{C}$. The supernatant was frozen at $-20^{\circ} \mathrm{C}$.

\section{RNA quality assessment using the AGILENT 6000 bioanalyser}

$1 \mu \mathrm{l}$ of RNA 6000 Nano dye concentrate was added to $65 \mu \mathrm{l}$ aliquot of filtered RNA 600 Nano gel, vortexed thoroughly and centrifuged for 10 minutes at 13000x $g$ while protecting it from light. The RNA Nano chip was placed on the chip priming station and $9 \mu \mathrm{l}$ of the gel-dye mix pipetted at the bottom of the well-marked 'G'. Using the plunger on the priming station the gel was dispersed across the chip. A further $9 \mu \mathrm{l}$ of the gel-dye mix was pipetted to the bottom of two other marked wells. $5 \mu$ of the RNA 6000 Nano marker was subsequently pipetted to the bottom of the well-marked with a ladder symbol and into each of the 12 sample wells (numbered 1-12). $1 \mu \mathrm{l}$ of the RNA ladder was pipetted to the well-marked with the ladder symbol and $1 \mu \mathrm{l}$ of RNA samples was placed in each sample well. The chip was vortexed (Vortexer, Agilent, Germany) for 60 seconds at $2400 \mathrm{rpm}$ (vortex "set point") and immediately inserted into the Bioanalyzer 2100 and run with "Eukaryotic RNA nano series II" program.

\section{Bacterial cell transformation using $\mathrm{DH} 5 \boldsymbol{\alpha}^{\mathrm{TM}}$ competent cells}

For each transformation reaction, $50 \mu \mathrm{l}$ of $\mathrm{DH} 5 \alpha^{\mathrm{TM}}$ cells was mixed with $1 \mathrm{ng}-10 \mathrm{ng}(1 \mu \mathrm{l}-5 \mu \mathrm{l})$ of plasmid DNA and placed on ice for 30 minutes. It was heated at $42^{\circ} \mathrm{C}$ for 20 seconds without shaking and placed on ice for 2 minutes. $950 \mu$ of pre-warmed luria broth was added to the bacterial cell/DNA mix and incubated at $37^{\circ} \mathrm{C}$ with shaking at 225 rpm for one hour. Two different volumes of the transformation reaction were collected and spread on two separate agar plates (prepared with 
the appropriate antibiotic) and left to dry in a hood for 20 minutes. The agar plates - wrapped to prevent desiccation - were incubated at $37^{\circ} \mathrm{C}$ overnight.

\section{Preparation of bacterial culture}

To make bacterial broth, $5 \mathrm{ml}$ Luria broth (and $5 \mu \mathrm{l}$ of appropriate antibiotic: $100 \mu \mathrm{g} / \mu \mathrm{l}$ for both kanamycin and ampicillin) was placed in a $10 \mathrm{ml} \mathrm{Grainer}{ }^{\mathrm{R}}$ tube. A single colony of bacterial cells growing on an agar plate was picked with a sterile yellow tip and the tip placed in the Grainer tube. This tube was then incubated with shaking $(225 \mathrm{rpm})$ (MaxQ, ThermoScientific, USA) overnight at $37^{\circ} \mathrm{C}$. Bacterial growth was evidenced by a cloudy medium.

\section{DNA quantitation with ultraviolet (UV) spectrophotometry (Nanodrop)}

The spectrophotometer was first blanked with $1.5 \mu$ l of RNAse free water then $1.5 \mu$ of each sample was placed on the cuvette and DNA concentration read off. Another blanking was done to clean out the cuvette.

\section{Plasmid restriction enzyme digestion and agarose gel electrophoresis}

Agarose (1\%) solution was prepared in TAE buffer, poured into a gel casting tray (ThermoFisher, USA) with combs already inserted and allowed to stand for 30 minutes. The tray was transferred to a horizontal electrophoresis tank (ThermoFisher, USA) and covered with TAE buffer solution. Samples (including loading buffer) already treated with digestion enzymes and SYBR green were loaded into the wells and electric field of $100 \mathrm{~V}$ applied in the dark for one hour. Nucleic acid bands post electrophoresis were visualised with the Odyssey infrared scanner (Licor, UK).

\section{Plasmid extraction using the endofree plasmid Maxiprep kit (QIAGEN ${ }^{\mathrm{TM}}$ )}

Large scale (maxi) preparation of plasmids was performed with the endofree plasmid maxi kit (Qiagen ${ }^{\mathrm{TM}}$ ) after confirming the plasmids via minipreparation, enzyme digest and gel electrophoresis, according to the manufacturer's recommendation.

\section{Transfection assays with plasmid expression vectors}

Incubated cells on achieving $40 \%$ - $80 \%$ single layer confluence were trypsinised and counted. An appropriate density of cells was diluted in antibiotic-rich medium and placed into each well of a 12 well plate. The cells were incubated with $5 \% \mathrm{CO}_{2}$ overnight at $37^{\circ} \mathrm{C}$. Transfection was performed on achieving $40 \%$ to $70 \%$ cell confluence. To prepare the transfection complexes, plasmid vector and transfection reagent (Attractene, Qiagen) suspensions were prepared individually using antibiotic - free medium and left to stand for 5 minutes at RT. The plasmid solution was mixed with attractene transfection reagent and incubated for a further 20 minutes at RT. Complete medium was added to make a final volume of $1000 \mu$ for each well of a 12 well plate. Culture medium from the incubated cells was removed and $1000 \mu \mathrm{l}$ of prepared transfection complexes placed in each well. The cells were incubated with $5 \% \mathrm{CO}_{2}$ at $37^{\circ} \mathrm{C}$ for a total of $48 \mathrm{~h}$ and transfection complexes removed and replaced with fresh medium after 12 hours of incubation.

\section{Transfection assays with small interfering RNA (siRNA)}

To prepare transfection complexes, siRNA (Dharmacon, ThermoScientific) and transfection reagent (DharmaFECT 1,
ThermoScientific) suspensions were prepared individually using serum - and antibiotic - free media and left to stand for 5 minutes at RT. siRNA dilution was mixed with the transfection reagent and incubated for 20 minutes at RT. Antibiotic-free medium was added to make a final volume of $1000 \mu \mathrm{l}$ for each well of a 12 well plate. Culture medium from the incubated cells was removed and $1000 \mu \mathrm{l}$ of prepared transfection complexes placed in each well. The cells were incubated with $5 \% \mathrm{CO}_{2}$ at $37^{\circ} \mathrm{C}$ for a total of $48 \mathrm{~h}-72 \mathrm{~h}$ and transfection complexes removed and replaced with fresh medium (antibiotic-free) after 12 hours of incubation. At the end of incubation, transfected cells were lysed for RNA extraction and QPCR or prepared for SDS-PAGE and subsequent western blotting.

Sodium dodecyl sulphate (SDS) - poly acrylamide gel electrophoresis (PAGE) and western blot analysis

Resolving buffer $(6 \%-8 \%)$ was poured between glass plates of the electrophoresis equipment (ThermoFisher, USA) and left to polymerise for 15 minutes. Stacking buffer was poured after inserting a 9 - well comb and left to stand for another $15 \mathrm{~min}$. Combs were removed and wells (covered with running buffer) washed and loaded with lysates. Electrophoresis was performed at 125 volts - 40 milliAmperes (mA) - 5 watts for two hours. Proteins were transferred from gels to polyvinylidene fluoride (PVDF) membrane (Millipore, USA) at $100 \mathrm{~mA}$ - 35 volts for 2 hours. The membrane was blocked with 3\% non-fat fresh milk (Marvel) for 2 hours and incubated with primary antibody overnight at $4{ }^{\circ} \mathrm{C}$. Further incubation with secondary antibody - horseradish peroxidase (HRP) labelled was performed for 2 hours at room temperature with shaking. The signal was detected using the ECL method.

\section{Stripping blot membranes}

Primary and secondary antibodies in blotted membranes were removed by placing the membrane in $100 \mathrm{ml}$ of warm $\left(55^{\circ} \mathrm{C}\right)$ strip buffer composite solution (4 g SDS, $1.4 \mathrm{ml} \beta$-mercaptoethanol, $1.51 \mathrm{~g}$ TRIS in $200 \mathrm{ml}$ distilled water) and rocked every 5-10 minutes. The membrane was washed for 10 minutes with PBS-T ( $\mathrm{pH} 7.5)$ and the incubation and wash steps repeated one more time.

\section{Complimentary DNA (cDNA) synthesis}

$1 \mu \mathrm{g}$ of RNA was denatured by heating at $70^{\circ} \mathrm{C}$ for 5 minutes and placed immediately on ice. It was mixed with $4 \mu \mathrm{l}$ of $5 \mathrm{x}$ cDNA synthesis buffers, $2 \mu \mathrm{l}$ of $500 \mu \mathrm{M}$ dNTP mix, $1 \mu \mathrm{l}$ of anchored oligodT primers (500 ng/ $\mu \mathrm{l}$ ), $1 \mu \mathrm{l}$ of $0.5 \mu \mathrm{M}$ Verso enzyme mix and $1 \mu \mathrm{l}$ of reverse transcriptase enhancer, all from the Verso cDNA kit (ThermoScientific, UK). The reaction mixture was made up to $20 \mu \mathrm{l}$ with RNAse free water and incubated in a PCR machine (Genestorm, England) at settings consistent with the manufacturer's instructions. The cDNA sample was saved at $-20^{\circ} \mathrm{C}$ for subsequent applications.

\section{Preparing primers for quantitative PCR (QPCR)}

To prepare $100 \mu \mathrm{M}$ solution of primer pair, the vial containing the dry primer powder was spun down and the recommended amount of RNAse free water (from technical sheet) was placed in the tube and mixed by inverting several times. The tube was kept on ice for 20 minutes, centrifuged again and stored at $-20^{\circ} \mathrm{C}$.

\section{Standard curve determination for QPCR efficiency}

A serial log dilution of CDNA for QPCR was obtained from neat to 1 $\times 10^{4}$ concentrations. QPCR was then performed as with the procedure below. A standard curve was automatically generated by the thermal cycler (CFX Connect ${ }^{\mathrm{TM}}$, Bio-Rad, USA). 


\section{Quantitative polymerase chain reaction (QPCR)}

Two wells (duplicate) of a 96 well plate were loaded with $5 \mu$ of a solution containing $5 \mu \mathrm{l}$ of Kapa mastermix, $3 \mu \mathrm{l}$ of diluted (1:5) cDNA, $3 \mu \mathrm{l}$ of RNAse - free water and $1 \mu \mathrm{l}$ of $10 \mu \mathrm{M}$ concentration of the relevant primer. The plate was centrifuged for one minute and loaded into the thermal cycler (CFX Connect ${ }^{\mathrm{TM}}$, Biorad, USA). The settings for the thermal cycler corresponded to the manufacturer's instructions for optimum temperatures for the Kapa mastermix.

\section{Results}

\section{CTCF plasmid DNA overexpression and siRNA knockdown optimisation}

To investigate the effect of CTCF on ERa expression we first determined the optimum conditions for CTCF plasmid DNA overexpression transfection assays by using varying amounts of plasmid DNA and attractene transfection reagent in $2.0 \times 10^{4} \mathrm{cells} / \mathrm{ml}$ of MCF7 cells. Lysates were prepared and proteins separated by SDS PAGE and blotted membranes probed serially with anti-CTCF (BD Biosciences, $0.5 \mu \mathrm{g} / \mathrm{ml}$ dilution), anti-ER (MA 310, ThermoScientific, $5 \mu \mathrm{g} / \mathrm{ml}$ ), antiER (Abcam 2647, $1 \mu \mathrm{g} / \mathrm{ml}$ ) and mouse monoclonal anti-actin (1:2000 dilution) antibodies. As shown in Figure 1A, 80\% CTCF protein overexpression was obtained compared to the empty vector plasmid using $1.2 \mu \mathrm{g}$ of plasmid DNA and $3 \mu \mathrm{l}$ of attractene. Shown also are extra protein bands at $\sim 120 \mathrm{kDa}$ in the lanes with overexpressed CTCF which could suggest that the extra CTCF protein produced by the cell on CTCF overexpression included isoforms with different molecular

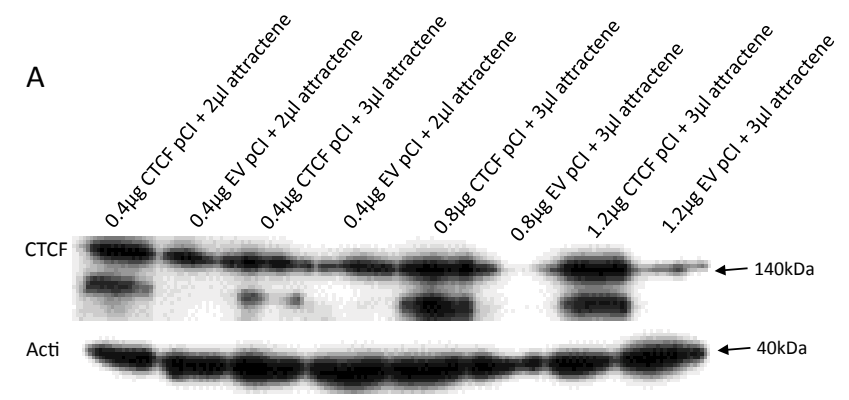

B

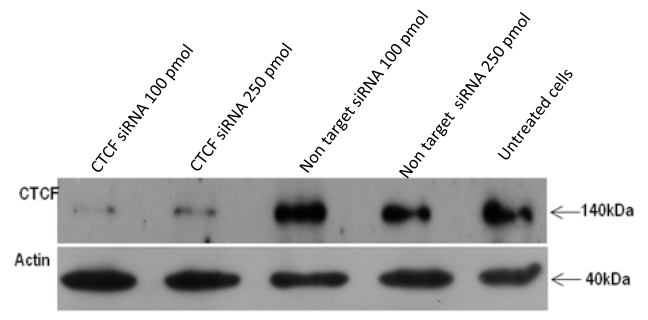

Figure 1: (A) Optimisation of MCF7 overexpression with a plasmid expression vector. The effect of different amounts of plasmid DNA (CTCF tagged and empty vector) and transfection reagent on CTCF protein expression is shown. Shown is about $80 \%$ CTCF protein overexpression using $1.2 \mu \mathrm{g}$ of DNA and $3 \mu$ l of attractene transfection reagent compared to $1.2 \mu \mathrm{g}$ of the empty vector (EV) pCl. (B) MCF7 cell RNA interference (RNAi) with CTCF and non-target siRNA. MCF7 cells treated with $100 \mathrm{pmol}$ and $250 \mathrm{pmol}$ of CTCF and nontarget siRNA using $2.66 \mu \mathrm{l}$ of DharmaFECT1 as transfection reagent and incubated for $72 \mathrm{~h}$. About $90 \%$ CTCF protein knockdown demonstrated with both siRNA concentrations. weights. No ERa expression was detected by western blotting however at any of the CTCF transfection conditions despite using up to three times the manufacturer's recommended anti-ERa antibody concentrations and with upwards of $50 \mu \mathrm{l}$ of cell lysate. This lack of visualisation was evident for both CTCF plasmid and empty vector control samples but not for untreated MCF7 whole cell lysates.

Similar experiments were performed to determine optimum CTCF siRNA knockdown conditions. $100 \mathrm{pmol}$ and 250 pmol respectively of CTCF siRNA and negative control non target siRNA were transfected with $2.66 \mu \mathrm{l}$ of DharmaFECT 1 transfection reagent for each well of a 12 well plate. As shown in Figure 1B, there was about 90\% knockdown of CTCF protein expression with CTCF siRNA compared to the nontarget siRNA and untreated MCF7 cells. As with the overexpression experiments, no protein bands were visualised on probing with antiERa antibodies for both siRNA and non-target control samples.

As ERa protein expression could not be determined by western blotting after cell transfection, further experiments studying gene expression were performed to determine whether CTCF overexpression/ knockdown had an effect on ERa gene expression. The combination of $1.2 \mu \mathrm{g}$ plasmid DNA, $3 \mu \mathrm{l}$ attractene transfection reagent and $2.0 \times 10^{4}$ cells/ml MCF7 cell density in a single well of a 12 well plate, incubated for 48 hours; and 250 pmol of CTCF siRNA, $2.66 \mu \mathrm{l}$ of DharmaFECT 1 transfection reagent, and $1.33 \times 10^{5} \mathrm{MCF} 7$ cell density in a single well of a 12 well plate, incubated for 72 hours, served as optimal conditions for CTCF transfection experiments.

Effect of transfection agents and reagents on MCF7 cell growth and viability

To determine the response of MCF7 cells to transfection reagents and confirm that cells were still viable after transfection, MCF7 cells were incubated with transfection reagents as shown in Figure 2. The concentrations and volumes of reagents used matched those used to achieve overexpression and knockdown in Figure 1A and 1B. Cell death manifested by cell rounding and loss of confluence was observed in cell panels incubated with CTCF pCI, EV pCI and CTCF siRNA. Ectopic expression of CTCF had previously been shown to profoundly inhibit cell growth with and without apoptosis [20,21]. It is however not clear why there was cell death with the EV pCI. Since CTCF expression was associated with cell survival it is not surprising that CTCF knockdown was associated with cell death. Using the trypan blue cell viability assay there was a $96.4 \%$ and $95.7 \%$ viability detected for MCF7 cells after $48 \mathrm{~h}$ (overexpression) and $72 \mathrm{~h}$ (knockdown) transfection incubation respectively (not shown). These numbers suggested that MCF7 cells remained viable post transfection allowing for further downstream processes.

\section{QPCR optimisation assays}

In order to further assess the effect of CTCF on ERa, gene expression studies were performed using QPCR following transfection of MCF7 cells with plasmid expression vectors and siRNA. On account of reproducibility issues associated with some QPCR data published in the literature, the Minimum Information for Publication of Quantitative Real-Time PCR Experiments (MIQE) guidelines [22] were used to determine the interplay between CTCF and ERa in this paper and included assessing RNA quality, primer structure and QPCR efficiency.

\section{Bioanalyser and Nanodrop estimation of RNA quality and} concentrations

Results in Figure S1a (supplementary file) show the quality of RNA 


\section{DINAmelt ${ }^{\mathrm{R}}$ prediction of secondary structures of primer \\ MCF7 \\ pairs for QPCR}

Overexpression

assays $(48 \mathrm{~h})$
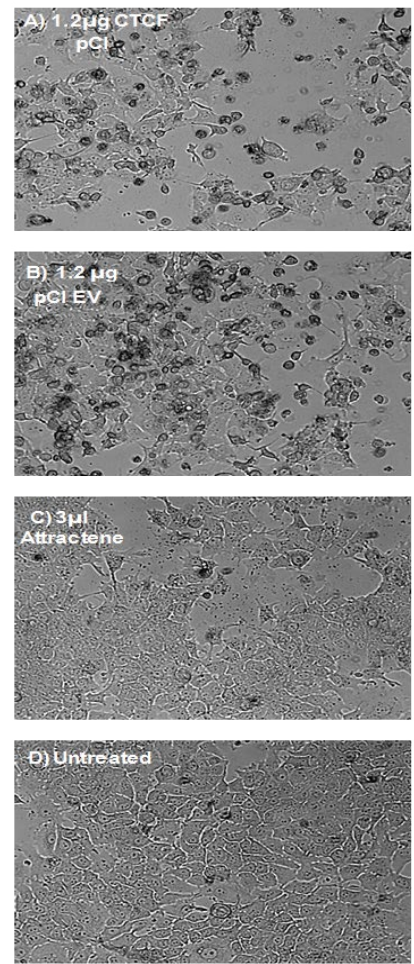

Figure 2: MCF7 cell response to expression vectors and attractene transfection reagent. Shown are MCF7 cells transfected with $1.2 \mu \mathrm{g}$ of CTCF pCi plus $3 \mu$ attractene (A), $1.2 \mu \mathrm{g}$ of EV pCi plus $3 \mu \mathrm{l}$ attractene (B), $3 \mu \mathrm{l}$ attractene alone (C) and no treatment (D) in the overexpression assays panels. Also MCF7 cells transfected with 250 pmol of CTCF siRNA using $2.66 \mu$ l DharmaFECT 1 (A); 250 pmol of non-target siRNA using $2.66 \mu$ l DharmaFECT 1 (B); $2.66 \mu \mathrm{l}$ DharmaFECT 1 only (C); and no treatment (D) in the knockdown assays panels. The panels show the extent of cell confluence and cell rounding (indicating cell death) on treatment and show some cell loss in cells transfected with plasmid expression vectors and CTCF siRNA.

samples used for QPCR in this paper and indicate two clear bands that represent the $18 \mathrm{~S}$ and $28 \mathrm{~S}$ ribosomal proteins in the densitometry plot. There were no extra bands suggesting the absence of contaminating nucleic acids in the samples. Further confirmation of RNA quality is shown in Figure S1b (supplementary file) which are spherograms generated by the bioanalayser by plotting the intensity of fluorescence with size/migration time of RNA in each sample. It confirmed the absence of nucleic acid contaminants by showing only two peaks which represent $18 \mathrm{~S}$ and $28 \mathrm{~S}$ RNA in all the samples. The bioanalyser was also used to estimate the RNA integrity number (RIN) and a number of 8 and over is taken as good RNA quality with a value of 10 the highest possible quality [23]. Table S1 (supplementary file) showed that the lowest RIN in the extracted RNA samples was 9.4 in the knockdown sample with CTCF siRNA. This result suggested that RNA used for the QPCR experiments was of pure quality with no contamination or degradation. This conclusion was further confirmed by the $260 / 280$ absorbance ratio determined by the Nanodrop spectrometer where the lowest absorbance ratio was 1.93 in the sample with EV pCI. A reading of between 1.8 and 2.0 is considered pure nucleic acid material [24]. Finally, RNA concentrations were estimated using the Nanodrop spectrometer and are also listed (supplementary file).
Proper primer annealing is required for reliable QPCR and exaggerated primer secondary structures could interfere with this process. The DINAmelt software was used to assess the extent of secondary structures of the primers used in this paper. Forward and reverse sequences of all primers used for QPCR were entered into the Two-state melting (folding) section of the DINAmelt software and assessed at temperature $=55^{\circ} \mathrm{C}$, magnesium $=5 \mathrm{nH}$, sodium $(\mathrm{Na})=50 \mathrm{nH}$ for RNA folding pattern [25]. As shown in Figure 6 (supplementary file), none of the primers possessed an exaggerated secondary structure predicting that there would be minimal primer interference.

\section{Standard curves and melting curves}

A linear standard curve with an amplification efficiency of $90 \%$ $-100 \%$, slope of -3.9 to -3.0 and $\mathrm{R}^{\wedge} 2$ value $>0.98$ (all influenced by replicate consistency) and single peak melting curves [22] combine to determine a fully validated QPCR assay. The result in Figure 3 showed that the standard curve for the CTCF primer pair (A) was linear and demonstrated a slope of $-3.369, \mathrm{R}^{\wedge} 2$ of 0.986 and efficiency of $98.1 \%$. The ERa primer pair (B) demonstrated a slope of $-3.406, \mathrm{R}^{\wedge} 2$ of 0.996 and efficiency of $96.6 \%$; GAPDH primer pair (C) had a slope of -3.343 , $\mathrm{R}^{\wedge} 2$ of 0.996 and an efficiency of $95.5 \%$; and TBP primer pair (D) showed a slope of $-3.367, \mathrm{R}^{\wedge} 2$ of 0.987 and efficiency of $98.2 \%$. These values were within expected limits for an accurately optimized QPCR assay. Furthermore, Figure 4 revealed single melt peaks confirming the presence of a specific nucleic acid product from a specific primer pair and that there was no contamination with other nucleic acid material.

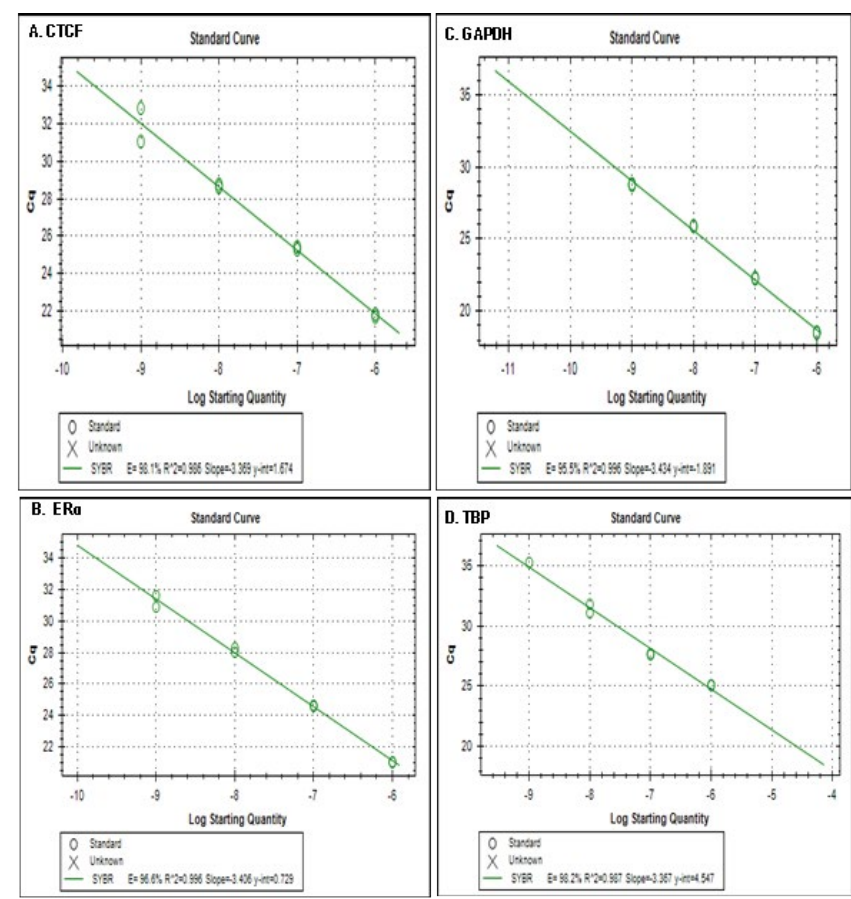

Figure 3: Standard curves for QPCR efficiency. MCF7 CDNA was reverse transcribed from $1 \mu \mathrm{g}$ of RNA and serially diluted 10 fold from neat to $1: 10$, 1:100 and 1:1000. Samples were amplified by QPCR with (A) CTCF, (B) ERa (C) GAPDH and (D) TBP primer pairs using Kapa mastermix. The reaction efficiency, slope and $R^{\wedge} 2$ values for each primer is indicated in the box for each graph. The values were within expected ranges for an accurately optimised QPCR assay. 


\section{Variation in CTCF mRNA expression and ERa gene expression response in MCF7 breast cancer cells}

Using the CTCF overexpression and knockdown conditions previously achieved, QPCR was performed to determine whether variation in CTCF mRNA affected the expression of ERa mRNA. The results in Table 1, achieved with QPCR conditions well within standard efficiencies as shown in the previous section, confirmed that CTCF overexpression $\Delta \mathrm{Cq}$ of 4.01 (fold change of 16.11) was associated with a $\Delta \mathrm{Cq}$ of -0.72 (fold change of 1.65) in ERa mRNA expression. Furthermore, CTCF knockdown $\Delta$ Cq of -2.11 (fold change of 4.32) was associated with just $\Delta \mathrm{Cq}$ of 0.17 (1.13 fold change) in ERa mRNA expression. The expression of reference genes GAPDH and TBP remained constant for both test material and controls in each set of experiments which indicated that the change(s) identified in CTCF and ERa expression were not due to variations in the general expression of RNA in the cells.

стеF
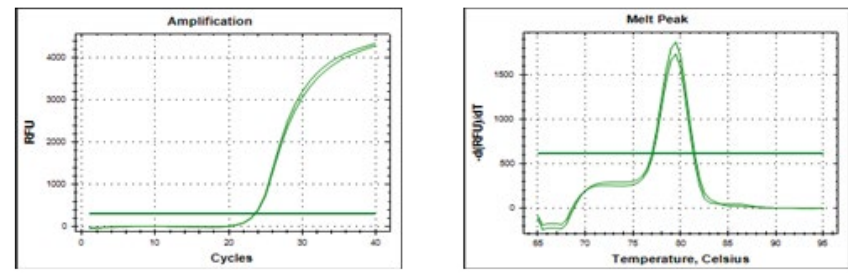

Estrogen Receptor a (ERa)
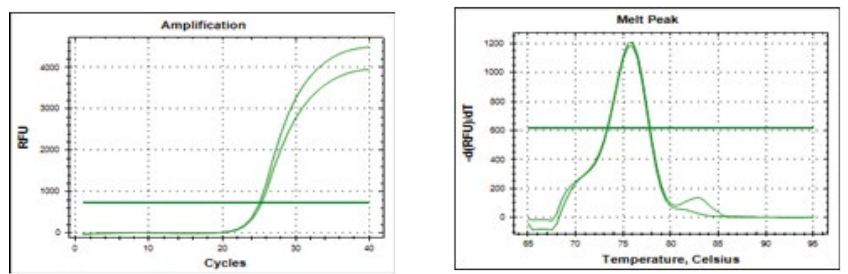

TBP
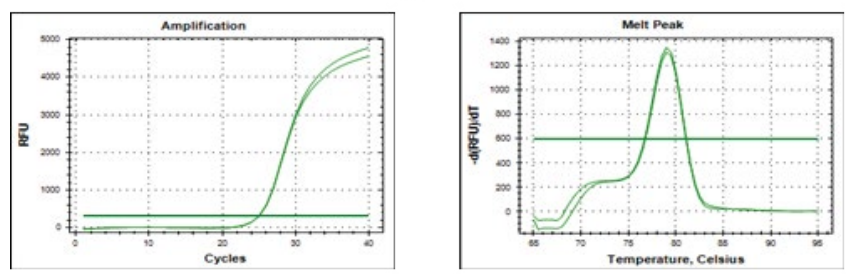

GAPDH
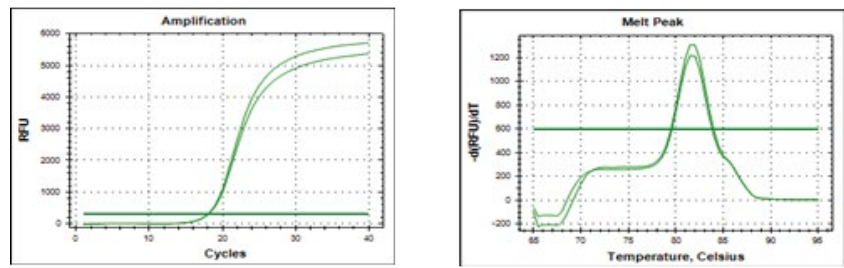

Figure 4: Assessment of QPCR replicate consistency and melting curves. MCF7 CDNA (reverse transcribed from $1 \mu \mathrm{g}$ of RNA) at 1:5 dilution was amplified in duplicates by QPCR using CTCF, estrogen receptor (ER) $\alpha$, TATA box protein (TBP) and GAPDH primer pairs respectively. The amplification curve indicating replicate consistency for each primer pair is shown. Also shown is the single peak melting point for each primer pair indicating the absence of nucleic acid contamination?

\section{Discussion}

The previous section revealed results we obtained while interrogating a possible regulatory impact of CTCF on ERa expression. MIQE guidelines were adhered to and we showed that RNA quality, primer secondary structure, reaction efficiency and primer melting points were all optimal for QPCR. The results revealed that MCF7 cells suffered some degree of cell death when subjected to transfection reagents. However, cell viability was sufficient for downstream processes. Also, an increase in CTCF mRNA expression occurred with a corresponding rise in CTCF protein expression and vice versa. Furthermore, transfection processes appeared to inhibit the ability to detect ERa protein expression in MCF7 cells. The results obtained however indicated that there was no direct regulatory effect of CTCF mRNA expression on ERa gene expression as neither a 16.11-fold overexpression of CTCF mRNA nor a 4.32-fold knockdown of CTCF mRNA had any discernible effect on ERa mRNA expression levels in MCF7 cells.

One main surprise in this paper was the inability to detect ERa protein expression in transfected MCF7 cells by western blotting though that expression had been detected in untreated whole cell lysates. Using augmented amounts of anti ERa antibody and different quantities of cell lysate did not make any difference. The reason for this finding is obscure and implicating antibody quality would not be justified as the anti ERa antibodies detected their associated protein in MCF7 whole cell lysates. There is evidence however suggesting that transfection processes could lead to unexpected abnormalities in cells which could include epitope masking. Evidence for this was suggested by Reynard, et al. [26] who studied the effect of a transfected membrane-bound glycoprotein (GP) in human embryonic kidney 293 (HEK293T) cells. The authors noted that while transfection of pCMLTrkA-GFP alone lead to a rise in TrkA and GFP on flow cytometry, cotransfection of phCMVGP and pCMLTrkA-GFP however gave rise to cells which while overexpressing GP and showing abundant GFP, revealed little TrkA expression. Using confocal microscopy, the authors found that cells overexpressing GP revealed very low TrkA surface staining though high levels of TrkA-

\begin{tabular}{|c|c|c|c|c|}
\hline & $\begin{array}{c}\text { Cq } \pm \text { SD } \\
\text { CTCF pCl }\end{array}$ & $\begin{array}{c}\text { Cq } \pm \text { SD } \\
\mathbf{E V ~ p C l}\end{array}$ & Cq change & Fold change \\
\hline CTCF & $17.005 \pm 0.0495$ & $21.015 \pm 0.0353$ & 4.01 & 16.11 \\
\hline ERa & $21.5 \pm 0.071$ & $20.78 \pm 0.0283$ & -0.72 & 1.65 \\
\hline GAPDH & $17.425 \pm 0.106$ & $17.175 \pm 0.064$ & -0.25 & \\
\hline TBP & $23.34 \pm 0.14$ & $22.745 \pm 0.191$ & -0.59 & \\
\hline
\end{tabular}

(A)

\begin{tabular}{|c|c|c|c|c|}
\hline & $\begin{array}{c}\text { Cq } \pm \text { SD } \\
\text { CTCF siRNA }\end{array}$ & $\begin{array}{c}\text { Cq } \pm \text { SD } \\
\text { Non target siRNA }\end{array}$ & Cq change & $\begin{array}{c}\text { Fold } \\
\text { change }\end{array}$ \\
\hline CTCF & $24.06 \pm 0.014$ & $21.945 \pm 0.078$ & -2.11 & 4.32 \\
\hline ERa & $20.835 \pm 0.219$ & $21.005 \pm 0.007$ & 0.17 & 1.13 \\
\hline GAPDH & $18.45 \pm 0.1697$ & $18.52 \pm 0.0567$ & 0.07 & \\
\hline TBP & $23.68 \pm 0.106$ & $23.455 \pm 0.0778$ & -0.22 & \\
\hline
\end{tabular}

(B)

Table 1: ERa mRNA fold change on CTCF overexpression and siRNA knockdown CTCF was overexpressed in MCF7 cells with a CTCF expression vector $(\mathrm{CTCF} \mathrm{pCl})$ and control empty vector $(\mathrm{EV}) \mathrm{pCl}(\mathrm{A})$ and underwent knockdown on transfection with CTCF siRNA and a control EV siRNA (B). CDNA was reverse transcribed from $1 \mu \mathrm{g}$ of extracted RNA and subjected to QPCR. Values are the average of two experiments, performed in duplicate. Table shows Cq levels for mRNA expression and fold changes for CTCF overexpression (A) and CTCF knockdown (B). Also shown are Cq levels for mRNA expression and fold changes for ERa and for reference genes GAPDH and TBP. A Cq change of less than 0.8 is accepted as 'no difference' in gene expression levels. The result indicates no significant change in ERa mRNA expression with significant fold changes in CTCF mRNA expression. 
GFP remained evident. They concluded therefore that overexpressed GP most likely masked the TrkA epitope and prevented its recognition by its antibody. The same could be adduced for the results in this paper though it wouldn't explain why CTCF knockdown should have a similar effect.

Another issue of note is the apparent discrepancy between the extent of CTCF mRNA fold change and the associated CTCF protein change. As seen in Figure 1A, $70 \%$ CTCF protein overexpression was, not surprisingly, associated with a 16.11-fold CTCF mRNA upregulation (Table 1). In contrast, $\sim 90 \%$ CTCF protein knockdown seen in Figure 1B was associated with only a 4.32 fold change in CTCF mRNA (Table 1). The latter result however is not without precedent. Using single molecule fluorescence in situ hybridization (smFISH) and RNA sequencing (RNA-seq), Taniguchi, et al. [27] showed an almost complete lack of correlation between mRNA and protein expression levels in their experiments on single cell protein concentrations. They suggested that this was due to the different life spans of mRNA and protein as the former is very readily broken down while proteins accumulated from cycle to cycle. At any given time point therefore the mRNA levels could appear significantly lower than the corresponding proteins translated from them.

This paper is probably the first to investigate a possible direct regulatory effect of CTCF gene expression change on ERa gene expression. Despite the previously described mutual interactions between CTCF and ERa, it is interesting, based on the results in this paper, that CTCF did not directly regulate ER $\alpha$ mRNA activity in the ER-positive MCF7 breast cancer cell line. It is possible that the previously mentioned interactions (see introduction) between CTCF and ERa could be limited in their application. For instance, the report of Ross-Ines was based on bioinformatics and may not reflect biologically significant endogenous interaction. Also the reported corecruitment of HDAC by CTCF and ERa was found after HDAC was overexpressed in the cell. This interaction could also be nonbiological as the HDAC protein expression would be grossly exaggerated in the cell. Moreover, the latter authors did not examine the opposite effect (HDAC1 knockdown) to determine whether the converse was true for the interaction they found. Taken together, it is possible to speculate that CTCF/ERa interaction could be an indirect effect mediated via protein partners or it might be that one protein initiates the event that leads to the recruitment of the other in an upstream/downstream interaction. The exact nature of the CTCF/ER $\alpha$ relationship obviously needs further enquiry.

\section{Conclusions}

We investigated the possibility of a direct regulatory relationship by CTCF on ERa expression at both the protein and mRNA level in the ER+ MCF7 breast cancer cell line. We found that ERa protein expression was not detectable by western blotting after MCF7 cell transfection and that variation in CTCF gene expression did not influence the expression of ERa mRNA. We speculate that the interaction between CTCF and ERa could be indirect, facilitated by protein partners.

\section{References}

1. Phillips JE, Corces VG (2009) CTCF: master weaver of the genome. Cell 137 1194-1211.

2. Wallace JA, Felsenfeld G (2007) We gather together: insulators and genome organization. Curr Opin Genet Dev 17: 400-407.

3. Zlatanova J, Caiafa P (2009) CTCF and its protein partners: divide and rule? J Cell Sci 122: 1275-1284.

4. El-Kady A, Klenova E (2005) Regulation of the transcription factor, CTCF, by phosphorylation with protein kinase CK2. FEBS Lett 579: 1424-1434.
5. Yang XJ, Chiang CM (2013) Sumoylation in gene regulation, human disease and therapeutic action. F1000Prime Rep 5: 45.

6. Docquier F, Kita GX, Farrar D, Jat P, O'Hare M, et al. (2009) Decreased poly(ADP-ribosyl)ation of CTCF, a transcription factor, is associated with breast cancer phenotype and cell proliferation. Clin Cancer Res 15: 5762-5771.

7. Liu S, Lin YC (2004) Transformation of MCF-10A human breast epithelial cells by zeranol and estradiol-17beta. Breast J 10: 514-521.

8. Russo J, Russo IH (2006) The role of estrogen in the initiation of breast cancer J Steroid Biochem Mol Biol 102: 89-96.

9. Acconcia F, Marino M (2011) The Effects of $17 \beta$-estradiol in Cancer are Mediated by Estrogen Receptor Signaling at the Plasma Membrane. Front Physiol 2: 30.

10. Ford CH, Al-Bader M, Al-Ayadhi B, Francis I (2011) Reassessment of estrogen receptor expression in human breast cancer cell lines. Anticancer Res 31: 521-527.

11. Park S, Koo JS, Kim MS, Park HS, Lee JS, et al. (2012) Characteristics and outcomes according to molecular subtypes of breast cancer as classified by a panel of four biomarkers using immunohistochemistry. Breast 21: 50-57.

12. Fuhrman BJ, Schairer C, Gail MH, Boyd-Morin J, Xu X, et al. (2012) Estrogen metabolism and risk of breast cancer in postmenopausal women. J Natl Cancer Inst 104: 326-339.

13. Yager JD, Davidson NE (2006) Estrogen carcinogenesis in breast cancer. N Engl J Med 354: 270-282.

14. Del Campo EP, Talamas Marquez JJ, Reyes-Vargas F, Del Pilar Intriago-Ortega M, Quintanar-Escorza MA, et al. (2014) CTCF and CTCFL mRNA expression in 17ß-estradiol treated MCF7 cells. Biomedical Reports 2: 101-104.

15. Rodriguez BA, Weng YI, Liu TM, Zuo T, Hsu PY, et al. (2011) Estrogen-mediated epigenetic repression of the imprinted gene cyclin-dependent kinase inhibito $1 \mathrm{C}$ in breast cancer cells. Carcinogenesis 32: 812-821.

16. Ross-Innes CS, Brown GD, Carroll JS (2011) A co-ordinated interaction between CTCF and ER in breast cancer cells. BMC Genomics 12: 593.

17. Hurtado A, Holmes KA, Ross-Innes CS, Schmidt D, Carroll JS (2011) FOXA1 is a key determinant of estrogen receptor function and endocrine response. Nat Genet 43: 27-33.

18. Kawai H, Li H, Avraham S, Jiang S, Avraham HK (2003) Overexpression of histone deacetylase HDAC1 modulates breast cancer progression by negative regulation of estrogen receptor. International Journal of Cancer 107: 353-358.

19. Lutz M, Burke LJ, Barreto G, Goeman F, Greb H, et al. (2000) Transcriptional repression by the insulator protein CTCF involves histone deacetylases. Nucleic Acids Research 28: 1707-1713.

20. Qi CF, Martensson A, Mattioli M, Dalla-Favera R, Lobanenkov VV, et al. (2003) CTCF functions as a critical regulator of cell-cycle arrest and death after ligation of the B cell receptor on immature B cells. Proc Natl Acad Sci U S A 100: 633-638.

21. Rasko JE, Klenova EM, Leon J, Filippova GN, Loukinov DI, et al. (2001) Cell growth inhibition by the multifunctional multivalent zinc-finger factor CTCF. Cancer Research 61: 6002-6007.

22. Bustin SA, Benes V, Garson JA, Hellemans J, Huggett J, et al. (2009) The MIQE guidelines: minimum information for publication of quantitative real-time PCR experiments. Clinical Chemistry 55: 611-622.

23. Schroeder A, Mueller O, Stocker S, Salowsky R, Leiber M, et al. (2006) The RIN an RNA integrity number for assigning integrity values to RNA measurements. BMC Mol Biol 7: 3

24. Fleige S, Pfaffl MW (2006) RNA integrity and the effect on the real-time qRTPCR performance. Mol Aspects Med 27: 126-139.

25. Markham NR, Zuker M (2005) DINAMelt web server for nucleic acid melting prediction. Nucleic Acids Res 33: W577-581.

26. Reynard O, Borowiak M, Volchkova VA, Delpeut S, Mateo M, et al. (2009) Ebolavirus glycoprotein GP masks both its own epitopes and the presence of cellular surface proteins. J Virol 83: 9596-9601.

27. Taniguchi Y, Choi PJ, Li GW, Chen H, Babu M, et al. (2010) Quantifying E. coli proteome and transcriptome with single-molecule sensitivity in single cells. Science 329: 533-538. 